\title{
Brain Development in Infantile-Onset Pompe Disease Treated by Enzyme Replacement Therapy
}

\author{
YIN-HSIU CHIEN, NI-CHUNG LEE, SHINN-FORNG PENG, AND WUH-LIANG HWU \\ Departments of Pediatrics and Medical Genetics [Y.-H.C., N.-C.L., W.-L.H] and Radiology [S.-F.P], National Taiwan University Hospital \\ and National Taiwan University College of Medicine, Taipei 10002, Taiwan
}

\begin{abstract}
The primary manifestations of Pompe disease are muscle weakness and cardiomyopathy. Although accumulation of glycogen has also been seen in the nervous system in patients, the significance of brain involvement in infantile-onset Pompe disease is not clear. In this study, brain development in five cases of infantileonset Pompe disease, whose survivals have been prolonged by enzyme replacement therapy (ERT), were studied by brain magnetic resonance imaging (MRI) and magnetic resonance spectroscopy (MRS). The results revealed delay in myelination milestones in all patients at a median age of 6 mo upon the initiation of treatment. After ERT, four of the five cases showed good progression in myelination, even though mild dilatation of the ventricles was still observed. In the case with no response to ERT in the muscles, however, brain myelination was slow and follow-up MRI and MRS studies suggested both neuron and myelination loss. Therefore, myelination defects are common in infantile-onset Pompe disease. Improvement in brain myelination could be seen in those who survive by effective treatment, although we do not know whether ERT does have a direct therapeutic effect on the brain. (Pediatr Res 60: 349-352, 2006)
\end{abstract}

$\mathrm{P}^{\mathrm{o}}$ ompe disease, or glycogen storage disease type II, is a lysosomal storage disorder caused by the deficiency of acid $\alpha$-glucosidase (GAA). Weakness of cardiac and skeletal muscles is the main symptom of the disease (1). In infantileonset Pompe disease, excessive glycogen storage can be seen in cardiac muscle, skeletal muscle, smooth muscle, and renal tubular epithelium (1). Glycogen accumulation has also been seen in glial cells in the brain cortex and brainstem and in anterior horn cells in the spinal cord in patients at autopsy $(2,3)$. In a study on the natural history of 20 cases of infantileonset Pompe disease, brain ultrasonography was performed in six cases and the results were all normal, but MRI performed in another two cases revealed widening of the anterior horns of the lateral ventricles and central cortical atrophy (4). Therefore, the significance of brain involvement in infantile-onset Pompe disease is still unclear, probably because most patients die before brain illness can be thoroughly investigated.

Received January 18, 2006; accepted May 10, 2006.

Correspondence: Wuh-Liang Hwu, M.D., Ph.D., Department of Pediatrics, National Taiwan University Hospital, 7 Chung-Shan South Road, Taipei 10002, Taiwan; e-mail: hwu@ha.mc.ntu.edu.tw

This study was partly supported by grants from the National Taiwan University Hospital (NTUH94S125, NTUH95M08).

DOI: $10.1203 / 01 . p d r .0000233014 .84318 .4 \mathrm{e}$
ERT with the recombinant human GAA (rhGAA) has yielded promising results in infantile-onset Pompe disease (5-7). The most remarkable effects from the treatment are improvement in cardiac function and survival. Some patients with early treatment have achieved good motor function and ambulation. However, because the intravenously replaced enzyme is unlikely to penetrate the blood-brain barrier, the accumulation of glycogen in the central nervous system becomes a concern when ERT prolongs the survival of the patients.

In this study, we have treated five patients with infantileonset Pompe disease and investigated brain development by MRI and MRS. Because of ERT, we had the chance to evaluate brain development in this disease for a longer period of time than previously.

\section{MATERIALS AND METHODS}

From December 2002 to December 2004, five cases (three boys and two girls) of infantile-onset Pompe disease were enrolled. The diagnosis of Pompe disease was established by the severe deficiency of GAA activity in both peripheral blood mononuclear cells and skin fibroblasts. All patients received rhGAA derived from Chinese hamster ovary cells (Genzyme Corporation). This study was approved by the Institutional Review Board of the National Taiwan University Hospital, and informed consent was obtained from the parents of each patient.

Brain MRI and MRS were done as described before (8). All patients and control subjects underwent MR examinations by using a 1.5-T MR machine (Sonata; Siemens, Erlangen, Germany) with the same parameters. In the MRS studies, the ratios $N$-acetyl aspartate (NAA) to creatine (Cre), NAA to choline (Cho), NAA to myoinositol (MI), MI to Cre, MI to Cho, and Cho to Cre were calculated.

Myelination milestones were determined by T1-weighted imaging for patients younger than 6 mo and then by T2-weighted imaging when patients reached 6 mo (9) and were as follows: high signal intensity on T1-weighted scans appears in the splenium corpus callosum by 4 mo, the genu by 6 mo, and adult pattern by $8 \mathrm{mo}$ and on T2-weighted imaging, myelination reaches the anterior limb of internal capsule at $11 \mathrm{mo}$, the subcortical white matter of the motor and visual area thereafter, and the deep frontal white matter (except the subcortical area) by age 24 mo (10).

\section{RESULTS}

All five patients were born full term with normal birth weight. Their median age at symptom onset was $3 \mathrm{mo}$, and

Abbreviations: Cho, choline; Cre, creatine; ERT, enzyme replacement therapy; GAA, acid $\alpha$-glucosidase; MI, myoinositol; MRS, magnetic resonance spectroscopy; NAA, $N$-acetyl aspartate; RhGAA, recombinant human GAA 
Table 1. Clinical information of the Pompe patients

\begin{tabular}{|c|c|c|c|c|c|c|c|c|}
\hline No. & Sex & $\begin{array}{c}\text { Age at } \\
\text { symptom } \\
\text { onset } \\
(\mathrm{mo})\end{array}$ & $\begin{array}{c}\text { Age } \\
\text { starting } \\
\text { ERT } \\
(\mathrm{mo})\end{array}$ & $\begin{array}{c}\text { Age at } \\
\text { first MRI } \\
(\mathrm{mo})\end{array}$ & $\begin{array}{c}\text { BW at } \\
\text { first MRI } \\
(\mathrm{kg})\end{array}$ & Motor development & $\begin{array}{c}\alpha \text {-Glucosidase } \\
\text { activity* }\end{array}$ & GAA gene mutation \\
\hline 1 & M & 3 & 6 & 6 & 6 & No antigravity arm movement & 0.03 & c. $1935 \mathrm{C}>\mathrm{A}(\mathrm{p} . \mathrm{D} 645 \mathrm{E}) / \mathrm{c} \cdot \mathrm{del} 2021-2023$ \\
\hline 2 & $\mathrm{~F}$ & 3 & 6 & 8 & 6.3 & Antigravity arm movement & 0.09 & c.1935C >A (p.D645E)/del exon3-exon15 \\
\hline 3 & $\mathrm{~F}$ & 4 & 5.5 & 5.5 & 6.5 & Antigravity arm movement & 0.06 & c.1935C >A (p.D645E)/c.1411-1414delGAGA \\
\hline 4 & M & 2 & 5.5 & 5.5 & 5.5 & Antigravity arm movement & 1.23 & c.872T $>$ C (p.L291P)/c.872T >C (p.L291P) \\
\hline 5 & M & 5 & 6 & 6 & 7.4 & Ambulatory & 0.57 & c. $1935 \mathrm{C}>\mathrm{A}(\mathrm{p} . \mathrm{D} 645 \mathrm{E}) / \mathrm{IVS} 78+2 \mathrm{~T}>2$ \\
\hline
\end{tabular}

* Activities in fibroblasts except for case 5 (mononuclear cells) (normal $>60 \mathrm{nmol} / \mathrm{mg}$ protein/h)

BW, body weight.

when rhGAA infusion started at a median age of 6 mo, all of them had hypotonia, hypertrophic cardiomyopathy, and mild failure to thrive (Table 1). After treatment for 12 mo, cardiomyopathy responded well, and the heart sizes of all patients decreased. Patient 5 gained good motor function, and he was ambulatory and could talk. All the other four patients were ultimately ventilated, but none of them has experienced severe hypoxia. There was a poor response to ERT in the muscles in cases 2, 3 and 4 . These three patients could do antigravity movements with their arms but not legs, and they did not have head control or could not sit. The patient in case 1 showed no response to ERT in the muscles and could move neither his arms nor legs antigravity. Nevertheless, there was no spasticity, rigidity, dystonia, or choreoathetosis in any of the patients. After ERT, none of them have inhibitory antibodies to rhGAA as tested by Genzyme Corporation.
Baseline MRI studies conducted at a median age of 6 mo upon the initiation of ERT revealed a delay in myelination in all cases (Table 2) because the myelination process could only be seen in the splenium of corpus callosum but not in the genu on T1-weighted images (Fig. 1). MRI performed after 6 mo of treatment (the median age was 13 mo) revealed progression in myelination in all cases. Myelination reached the genu of corpus callosum in case 1; reached anterior limb of internal capsule in cases 2, 3, and 4; and arrived in subcortical white matter at motor and visual cortex in case 5 (Table 2). However, structural abnormalities including mild dilatation of the lateral ventricles could be visualized in three cases (Fig. 1, cases 1-3). MRI studies at 18 mo of age revealed that myelination reached the subcortical white matter of the motor and visual cortices in all patients except the patient in case 1 .

Table 2. MRI findings in Pompe patients

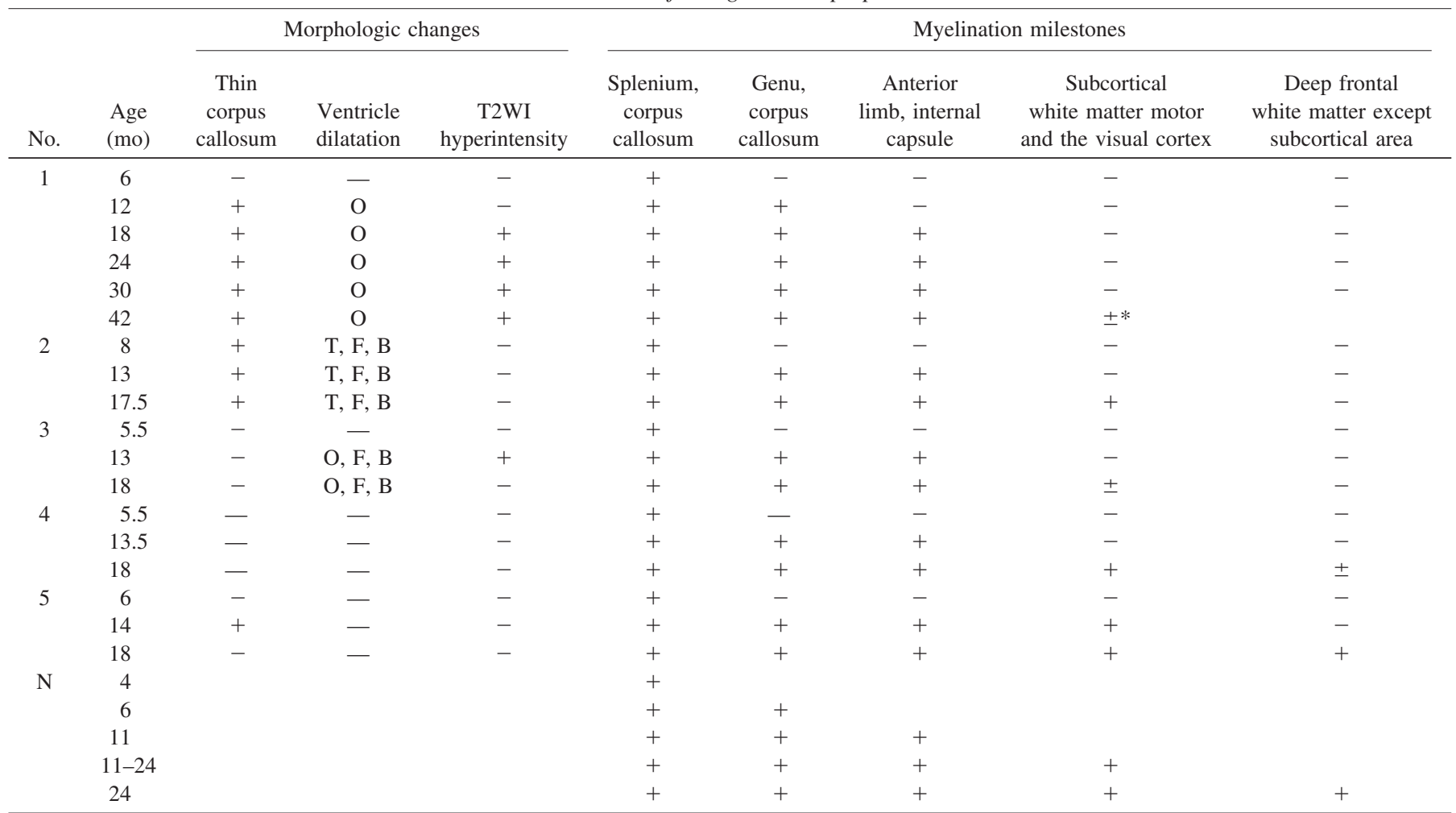

* Incomplete pattern.

T2WI, T2-weighted imaging; O, occipital horn; T, temporal horn; F, frontal horn; B, body; N, Normal. 


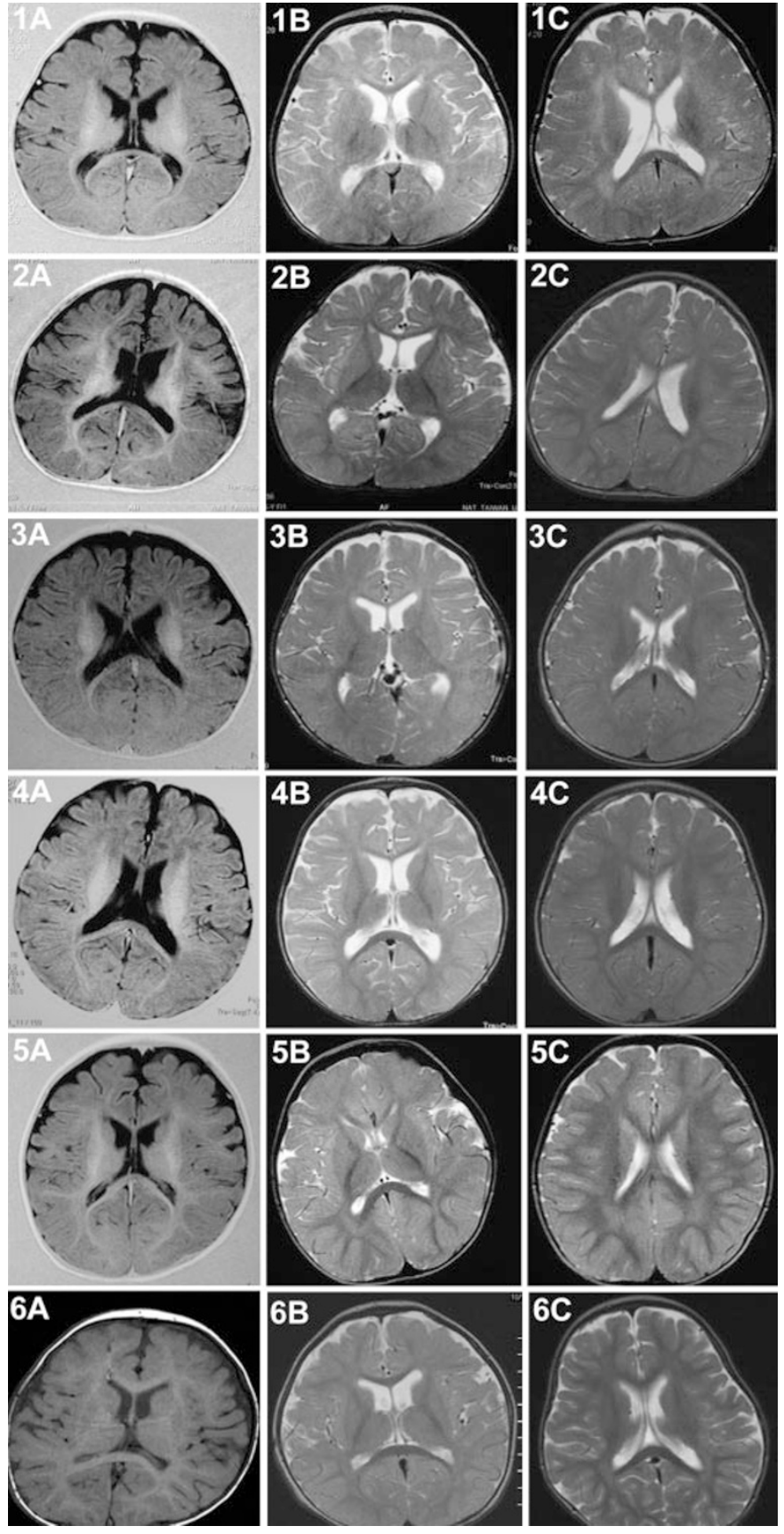

Figure 1. Brain MRI for five infantile-onset Pompe disease patients (rows $1-5$, respectively) and normal myelination pattern of the specific ages (row 6). Column A contains T1-weighted images at the ages of around 6 mo (before treatment) except $2 \mathrm{~A}$, in which MRI was performed 2 mo after therapy. Columns $B$ and $C$ contain T2-weighted images at the ages of around $12 \mathrm{mo}$ (6 mo after treatment) and 18 mo (12 mo after treatment), respectively. For details, please refer to Table 2 . The planes are selected for images with the most information.
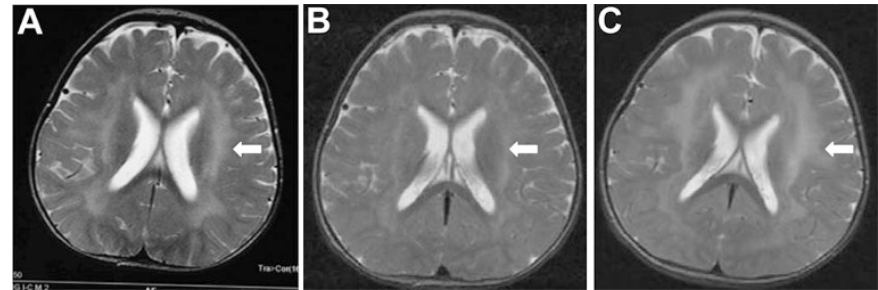

Figure 2. Brain MRI in case 1. T2-weighted images were obtained at the age of $24(A), 30(B)$, and $42(C)$ months. All images revealed prominent ventricles, poor myelination, and periventricular high-density signals (arrows).

The patient in case 1, who has the worst outcome among the five cases, has been followed for another 24 mo by MRI. His brain myelination process was slow since the first study at 6 mo of age, and there was almost no further improvement in myelination after age 18 mo. Furthermore, abnormal highdensity signals on T2-weighted images were also evident in the white matter since 18 mo of age (Figs. 1 and 2). These high-density lesions on T2-weighted images may suggest a demyelinating or dysmyelinating processes. MRS study revealed low NAA/Cre, NAA/Cho, and NAA/MI ratios at 6 mo. These ratios increased at the 12- and 18-mo studies, but dropped again at 24 mo (Table 3). Normally, the NAA/Cr ratio increases from age 1 mo to 1 or 2 y (11), and a decrease in NAA usually suggests neuronal loss (12). However, even though he had profound muscle weakness, he was rather stable under ventilator therapy. Therefore, those MRI and MRS changes were difficult to explain by poor general condition.

\section{DISCUSSION}

Infantile-onset Pompe disease (defined as disease onset before $1 \mathrm{y}$ of age) is an early-onset fatal disease in infants. In one study on the natural course of this condition, symptoms started at a median age of $1.6 \mathrm{mo}$, and death occurred at a median age of 6 mo (4). In the current study, all patients had the diagnosis before 6 mo of age, and therefore they were classic cases of infantile-onset Pompe disease. Because of the treatment, their survivals were already much longer than what could be expected from the natural history study. Therefore, we had the chance to see brain images beyond infancy in infantile-onset Pompe disease.

Deposition of glycogen in oligodendrocytes has been identified as early as the second trimester of gestation in the affected fetus (13), and the infoldings of the myelin contained glycogen-filled projections of the cytoplasm of Schwann cells may interfere with the formation of myelin (14). In the current

Table 3. MRS findings in case 1

\begin{tabular}{cccccc}
\hline $\begin{array}{c}\text { Age at } \\
\text { MRI }(\mathrm{mo})\end{array}$ & NAA/Cre (normal) & NAA/Cho (normal) & NAA/MI (normal) & MI/Cre (normal) & Cho/Cre (normal) \\
\hline 6 & $0.62(1.33 \pm 0.06)$ & $0.61(1.31 \pm 0.41)$ & $1.57(3.51 \pm 0.07)$ & $0.39(0.38 \pm 0.02)$ & $1.01(1.06 \pm 0.29)$ \\
12 & $1.09(1.47 \pm 0.22)$ & $1.04(2.05 \pm 0.49)$ & $2.96(3.95 \pm 2.09)$ & $0.37(0.45 \pm 0.21)$ & $1.05(0.73 \pm 0.09)$ \\
18 & $2.12(1.48 \pm 0.19)$ & $3.88(2.05 \pm 0.52)$ & $9.58(4.38 \pm 0.87)$ & $0.22(0.38 \pm 0.21)$ & $0.54(0.76 \pm 0.28)$ \\
24 & $0.72(1.61 \pm 0.24)$ & $1.06(1.89 \pm 0.29)$ & $2.37(4.58 \pm 0.62)$ & $0.30(0.40 \pm 0.06)$ & $0.67(0.97 \pm 0.02)$ \\
\hline
\end{tabular}


study, all five cases demonstrated a delay in myelination at the age of 6 mo (15). Lee et al. (16) has described the MRI findings in one 5-mo-old patient as myelination of the cerebral white matter that was normal for age on T2-weighted images, even though glycogen deposition in the dura was suspected at the same time. Because during early infancy, signal intensity on T1-weighted images increases because of an increase in cholesterol and glycolipids that accompanies the formation of myelin from oligodendrocytes $(9,17)$, it would be better to judge myelination progress by $\mathrm{T} 1$-weighted images for patients younger than 6 mo (10). In three of our five patients, dilatation of the ventricles was also found. Therefore, brain involvement could be common in infantile-onset Pompe patients. Because the general conditions of our patients were stable at the time of the first MRI evaluation, we suggest that the brain involvement was more likely related to specific pathologies of Pompe disease.

Early brain involvement in neurodegenerative diseases usually indicates rapid degeneration in the near future. However, we were fairly encouraged by the good progression of brain myelination in most patients. Currently, there is no evidence that ERT could benefit brain diseases, except in Fabry disease in which endothelium deposition is the main pathogenesis (18). However, in view of the very large amount of enzyme $(20 \mathrm{mg} / \mathrm{kg}$ ) infused every $2 \mathrm{wk}$, it may be that a small amount of enzyme did penetrate the blood-brain barrier and reach the brain. On the other hand, it should be more likely that brain involvement in Pompe disease is a benign or self-limited process and that brain development could continued as long as the patients survive in good health.

In this report, we demonstrated that delay in myelination is common in infantile-onset Pompe disease, but this early appearance of brain lesions does not necessarily indicate poor brain prognosis as long as the patients respond to ERT. Further studies will be necessary to clarify the pathologies and long-term prognosis of the disease in the central nervous system.

\section{REFERENCES}

1. Hirschhorn R 2001 Glycogen storage disease type II: acid-glucosidase (acid maltase) deficiency. In Scriver CS, Sly WS, Valle D (eds) The metabolic and molecular bases of inherited disease. McGraw-Hill, New York, pp 3389-3420

2. Gambetti P, DiMauro S, Baker L 1971 Nervous system in Pompe's disease. Ultrastructure and biochemistry. J Neuropathol Exp Neurol 30:412-430

3. Sakurai I, Tosaka A, Mori Y, Imura S, Aoki K 1974 Glycogenosis type II (Pompe). The fourth autopsy case in Japan. Acta Pathol Jpn 24:829-846

4. van den Hout HM, Hop W, van Diggelen OP, Smeitink JA, Smit GP, Poll-The BT, Bakker HD, Loonen MC, de Klerk JB, Reuser AJ, van der Ploeg AT 2003 The natural course of infantile Pompe's disease: 20 original cases compared with 133 cases from the literature. Pediatrics 112:332-340

5. Chen YT, Amalfitano A 2000 Towards a molecular therapy for glycogen storage disease type II (Pompe disease). Mol Med Today 6:245-251

6. Van den Hout H, Reuser AJ, Vulto AG, Loonen MC, Cromme-Dijkhuis A, Van der Ploeg AT 2000 Recombinant human alpha-glucosidase from rabbit milk in Pompe patients. Lancet 356:397-398

7. Van den Hout JM, Reuser AJ, de Klerk JB, Arts WF, Smeitink JA, Van der Ploeg AT 2001 Enzyme therapy for pompe disease with recombinant human alphaglucosidase from rabbit milk. J Inherit Metab Dis 24:266-274

8. Chien YH, Peng SF, Wang TR, Hwu WL 2002 Cranial MR spectroscopy of tetrahydrobiopterin deficiency. AJNR Am J Neuroradiol 23:1055-1058

9. Barkovich AJ, Kjos BO, Jackson DE Jr, Norman D 1988 Normal maturation of the neonatal and infant brain: MR imaging at $1.5 \mathrm{~T}$. Radiology 166:173-180

10. Barkovich AJ, Kjos BO 1988 Normal postnatal development of the corpus callosum as demonstrated by MR imaging. AJNR Am J Neuroradiol 9:487-491

11. Hashimoto T, Tayama M, Miyazaki M, Fujii E, Harada M, Miyoshi H, Tanouchi M, Kuroda Y 1995 Developmental brain changes investigated with proton magnetic resonance spectroscopy. Dev Med Child Neurol 37:398-405

12. Zimmerman RA, Wang ZJ 1997 The value of proton MR spectroscopy in pediatric metabolic brain disease. AJNR Am J Neuroradiol 18:1872-1879

13. Chen CP, Lin SP, Tzen CY, Tsai FJ, Hwu WL, Wang W 2004 Detection of a homozygous D645E mutation of the acid alpha-glucosidase gene and glycogen deposition in tissues in a second-trimester fetus with infantile glycogen storage disease type II. Prenat Diagn 24:231-232

14. Araoz C, Sun CN, Shenefelt R, White HJ 1974 Glycogenosis type II (Pompe's disease): ultrastructure of peripheral nerves. Neurology 24:739-742

15. Yamada H, Sadato N, Konishi Y, Muramoto S, Kimura K, Tanaka M, Yonekura Y, Ishii Y, Itoh H 2000 A milestone for normal development of the infantile brain detected by functional MRI. Neurology 55:218-223

16. Lee CC, Chen CY, Chou TY, Chen FH, Lee CC, Zimmerman RA 1996 Cerebral MR manifestations of Pompe disease in an infant. AJNR Am J Neuroradiol 17:321-322

17. Kondo A, Sato Y, Nagara H 1991 An ultrastructural study of oligodendrocytes in Zitter rat: a new animal model for hypomyelination in the CNS. J Neurocytol 20:929-939

18. Jardim L, Vedolin L, Schwartz IV, Burin MG, Cecchin C, Kalakun L, Matte U, Aesse F, Pitta-Pinheiro C, Marconato J, Giugliani R 2004 CNS involvement in Fabry disease: clinical and imaging studies before and after 12 months of enzyme replacement therapy. J Inherit Metab Dis 27:229-240 